Sains Malaysiana 48(5)(2019): 1011-1018

http://dx.doi.org/10.17576/jsm-2019-4805-09

\title{
Development of an HPLC Method for Formic Acid Analysis through Peak Exclusion Approach
}

(Pembangunan Kaedah HPLC bagi Analisis Asid Formik melalui Pendekatan Pengecualian Puncak)

\author{
DANIYAL HASAN, IRAM MAHMOOD*, ISHFAQ AHMAD, FARAH AZIZ \& ISHAQ AHMAD
}

\begin{abstract}
High Performance Liquid Chromatography (HPLC) is a chemical analysis technique that gives both the quantitative and qualitative analysis of liquid samples. A certain set of parameters, called HPLC method, are defined for analysis of every discrete mixture. Often literature is not available or specifically reported expensive HPLC apparatus is not available for every set of mixtures. Present study concentrated on analysis of formic acid from a mixture of methanol, formaldehyde and water. Formic acid is a basic carboxylic acid that has growing industrial and commercial uses, especially as a refrigerant. A C-18 column was utilized for the analysis by optimizing the parameters like dimensions of the stationary column, nature of mobile phase, flow rate of mobile phase and wavelength of the ultraviolet detector. Comprehendible and reproducible results for the analysis of formic acid were obtained on $25 \mathrm{~cm}$ long $C-18$ stationary column, by tuning the combined effect of water as mobile phase at a flow rate of $1 \mathrm{~mL} / \mathrm{min}$ and by excluding the unnecessary peaks at 250 $n m$ wavelength of ultraviolet detector, called peak exclusion approach. The calibration curve was found to be linear over the range of $1.25 \% \mathrm{v} / \mathrm{v}$ formic acid solution in methanol up to $100 \%$ pure formic acid. Limit of detection (LOD) and limit of quantitation ( $L O Q)$ were found to be $2.25 \%$ and $6.83 \%$, respectively.
\end{abstract}

Keywords: C-18 columns; calibration; flow rate; formic acid; peak exclusion

\section{ABSTRAK}

Kromatografi Cecair Prestasi Tinggi (HPLC) adalah teknik analisis kimia yang memberikan analisis kuantitatif dan kualitatif bagi sampel cecair. Satu set parameter yang dipanggil kaedah HPLC ditakrifkan untuk analisis setiap campuran diskret. Selalunya, kajian kepustakawan tidak diperoleh atau dilaporkan secara khusus untuk setiap set campuran kerana radas HPLC yang mahal. Kajian terkini tertumpu kepada analisis asid formik daripada campuran metanol, formaldehid dan air. Asid formik adalah asid karboksilik asas yang digunakan secara meluas di dalam industri dan komersial, khususnya sebagai bahan penyejuk. Kolum C-18 telah digunakan untuk analisis dengan mengoptimumkan parameter seperti dimensi kolum pegun, jenis fasa mudah alih, kadar aliran fasa mudah alih dan panjang gelombang pengesan ultraungu. Keputusan yang boleh difahami dan boleh ulang untuk analisis asid formik telah diperoleh pada $25 \mathrm{~cm}$ panjang kolum pegun C-18, oleh penalaan kesan gabungan air sebagai fasa bergerak pada kadar aliran $1 \mathrm{~mL} / \mathrm{min}$ dan tidak termasuk puncak tak perlu pada $250 \mathrm{~nm}$ panjang gelombang pengesan ultraungu, dikenali sebagai pendekatan pengecualian puncak. Lengkung tentukuran didapati linear ke atas julat larutan asid formik $1.25 \% \mathrm{v} / \mathrm{v}$ dalam metanol sehingga $100 \%$ asid formik tulen. Had pengesanan (LOD) dan had pengiraaan (LOQ) masing-masing ialah $2.25 \%$ dan $6.83 \%$.

Kata kunci: Asid formik; kadar aliran; kolum C-18; penentukuran; pengecualian puncak

\section{INTRODUCTION}

High Performance Liquid Chromatography (HPLC), is also referred as High-Pressure Liquid Chromatography for the high working pressure. It is an analytical technique, in which the constituents of an otherwise inseparable chemical mixture are analyzed both qualitatively and quantitatively (Hostettmann et al. 1998). Constituents are carried by a mobile carrier phase or solvent on a stationary column. Depending on the nature of the column packing and the mobile phase, the constituents have different affinities towards the material of the column and under high pressure; the constituent molecules are forced through a packed column that separate the mixture on the basis of size and the nature. Based on the difference in affinity of each species within the stationary column, they are retained on the column for different times and each species elute one by one, the one having highest affinity elutes last (McMurry 2011). The detector attached to the HPLC unit generates ultraviolet rays of particularly specified wavelength and the eluting sample is subjected to these ultraviolet rays. Molecules of the eluting species get excited by absorbing the energy of the ultraviolet rays, during the process of de-excitation energy is released which is being recorded by the detector (Taylor 2015). A signal proportional to 
the energy change is generated and recorded in the form of a graph called chromatogram. The absorption of the ultraviolet rays depends on the functional group of the eluting species, because every functional group requires a particular amount of energy for its excitation, which is carried by ultraviolet light of a certain wavelength. However, sometimes specifically reported costly apparatus is often not available in the research labs. To achieve the desired analysis on the available set of apparatus, certain parameters need to be tuned, this is called HPLC method development. In this paper, we have demonstrated the impact of each parameter and the required approach to tune it for formic acid analysis.

Several methods for the determination of formic acid have been reported (Lee et al. 2013; Mubeen et al. 2011). However, the reported apparatus was not available in the laboratory. The desired separation was achieved on the available C-18 column, which is usually used for the separation of polar organic compounds. Choice of mobile phase and its flow rate were adjusted to achieve the separation. Wavelength of the detector was tuned to identify formic acid. The results were reported to elaborate the importance and effect of each parameter, thereby giving a guideline to achieve any separation on a given set of resources.

\section{MATERIALS AND METHODS}

\section{MATERIALS}

All the chemicals were of commercial grade and highest purity available including: Formic acid $94 \mathrm{w} / \mathrm{w}$ percent (Sigma Aldrich); HPLC grade methanol (Sigma Aldrich); Formaldehyde (Merck); Acetonitrile (Sigma Aldrich); HPLC grade water (Sigma Aldrich). Perkin-Elmer, 200 series, HPLC module coupled with Ultraviolet detector and auto sampler, was used for the analysis. Octadecylsilane (C-18) columns of dimensions (250 mm length $\times 3 \mathrm{~mm}$ ID $\times 5 \mathrm{~mm}$ particle size $)$ and $(100 \mathrm{~mm}$ length $\times 3 \mathrm{~mm} \mathrm{ID} \times$ $5 \mathrm{~mm}$ particle size) were used.

\section{HPLC ANALYSIS METHOD}

To test the required dimensions of the column, formic acid solution $(50 \% \mathrm{v} / \mathrm{v}$ in methanol) was run on $\mathrm{C}-18$ columns of $10 \mathrm{~cm}$ and $25 \mathrm{~cm}$ length. Formic acid, methanol and formaldehyde were used as solvents using water, methanol and acetonitrile as mobile phase $(25 \mathrm{~cm} \mathrm{C}-18$ column). Flow rate was used in the range of 0.5 to 1.5 $\mathrm{mL} / \mathrm{min}$. Wavelength was varied between the maximum absorption spectrum of methanol $(205 \mathrm{~nm})$ and maximum absorption spectrum of formic acid $(256 \mathrm{~nm})$. The other parameters were kept constant with water as solvent at a flow rate of $1 \mathrm{~mL} / \mathrm{min}$ over $25 \mathrm{~cm}$ long C-18 column. Samples of formic acid in water, with concentrations varying from $1.25 \%$ to $100 \%$, were used to obtain a calibration curve.

\section{RESULTS AND DISCUSSION}

\section{HPLC COLUMN}

An HPLC column provides the necessary structure which has varying affinities for different species and will separate them by holding them for varying retention time (Ettre et al. 1993). The column is selected on the basis of species in the mixture; this choice is made based upon the columns reported in literature for the separation of similar species. Different combinations of columns and mobile phases could be used to achieve the same separation; however the efficiency of separation and resolution of peaks would be different for different peaks. Mubeen et al. (2011) have reported the use of normal phase hyper silica column for the separation of formic acid and imidurea; however, the method was reported to be valid specifically for the mixtures of formic acid and imidurea. For the separation of polar species, reverse phase chromatography is generally preferred where polar species are separated by using a combination of a non-polar column and a polar solvent (McNaught et al. 1997). Reversed phase columns, especially C-18 column, in combination with water as mobile phase have been reported to achieve similar separation (Krummen et al. 2004; Levigne et al. 2002) and $\mathrm{C}-18$ column is reported to have an appropriate retention time at high concentrations of formic acid (Tagami et al. 2008). Available C-18 columns were tested to achieve the separation, which gave the better separation of methanol and formic acid, as C-18 column has a larger structure providing a suitable molecular structure over which the species having close difference of polarity and functional groups could be separated.

\section{LENGTH OF COLUMN}

Length of column is critical to provide sufficient space over which the components of a mixture would bind to the material of the column and get separated. If the column is small, then it would not provide enough space to separate the constituents of the sample. If the column is very large, then the analysis of each sample would take a lot of time and would also result in the loss of larger quantity of solvent to completely wash the column for next analysis. Two different lengths of C-18 column were tested, i.e. 10 $\mathrm{cm}$ and $25 \mathrm{~cm}$. Comparison of separation efficiencies has been shown in Figure 1.

Peaks with $10 \mathrm{~cm}$ column appeared about $1 \mathrm{~min}$ retention time, were closely spaced and irregular. $25 \mathrm{~cm}$ long column provided enough space to achieve complete separation, and the peaks appeared after 4 min retention time and were well separated from each other.

\section{SOLVENT}

Choice of solvent is also very important for the clear identification of each component of the mixture. Sometimes, solvents may react with some of the components, which can have two possible outcomes: Component can become 
(a)

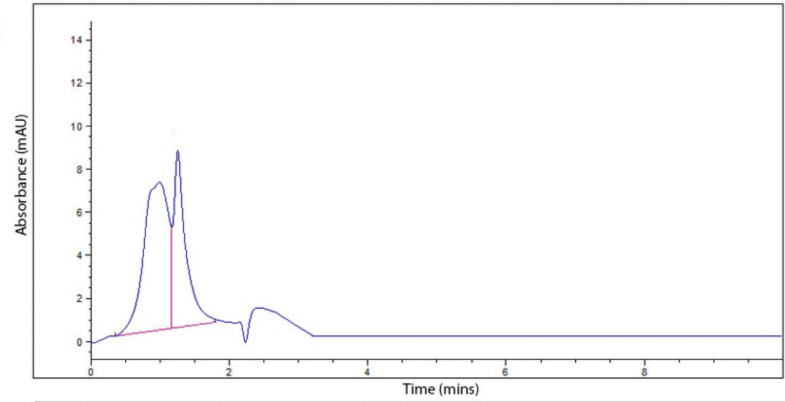

(b)

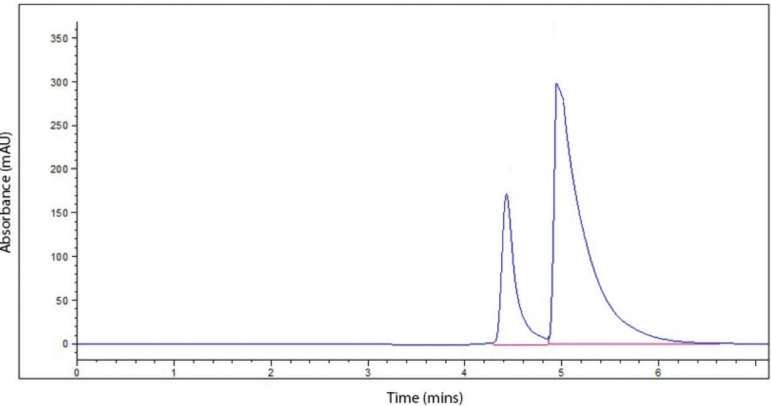

FIGURE 1. Comparison of separation efficiencies on columns of different lengths (a) $10 \mathrm{~cm}$ and (b) $25 \mathrm{~cm}$ long C-18 column

undetectable and thus the peak could get excluded from the chromatogram. However, in cases where the component is not easily detectable then, the solvent is chosen so that it forms a detectable complex with the component of interest. The interaction of the components with the solvent is also controlled by changing the $\mathrm{pH}$ of the solvent, which changes the polarity and the nature of the solvent, thus, the detectability of the component is improved as desired. Water, methanol, acetonitrile or any concentration of their mixture is generally used for the reverse phase HPLC. During experiments, pure methanol was tested as a solvent, also because it would exclude one of the components present in the sample i.e. methanol; however, it did not give any detection for formic acid which had been the main component of interest. Acetonitrile was tried as a solvent but it also did not give any detection. Water gave clear identification for the standard samples of methanol and formic acid; However, it did not give any peak with standard samples of formaldehyde because formaldehyde reacted with water and formed diol, which is a characteristic property of aldehydes, and became undetectable because of the presence of methanol having the same functional group. A solution of $50 \% \mathrm{v} / \mathrm{v}$ methanol in water was also used but a clear peak of formic acid did not appear on the chromatogram.

\section{FLOW RATE OF THE SOLVENT}

Beside the nature of the solvent, which provides the force of attraction that separates the constituents of a sample on the column, the flow rate of the solvent is also important to provide the time necessary to separate the constituents and to carry out the sample over the entire column. If the flow rate is high, then the constituents of the sample are not separated enough to be detected separately. If the flow rate is very low, then the species would be clearly separated but then each run of the sample would require a longer time and the constituents of the sample would not completely elute out of the column. Hence, a suitable flow rate is adjusted where the required separation would be achieved and the constituents would also be completely eluted out of the column. Flow rate of the solvent is also important in the situation, where a certain column of reported dimensions is not available in the lab; then flow rate of the solvent could be adjusted to provide the necessary time for separation and achieve the separation using the given apparatus.

Initially a flow rate of $1.5 \mathrm{~mL} / \mathrm{min}$ was selected and the formic acid peak appeared around retention time of $1 \mathrm{~min}$. The flow rate was then decreased to $1 \mathrm{~mL} / \mathrm{min}$ and the peaks appeared around retention time of $3.5 \mathrm{~min}$. Flow rate of $0.5 \mathrm{~mL} / \mathrm{min}$ was also tested and the peaks appeared around retention time of $6 \mathrm{~min}$. Solvent flow rate was adjusted at $1 \mathrm{~mL} / \mathrm{min}$ to achieve the given separation. Changes in retention time with change in solvent rate have been shown in Figure 2. The similar trend of decrease in retention time with the increase in flow rate has also been reported by Mubeen et al. (2011).

\section{WAVELENGTH OF UV DETECTOR}

A detector is the last part in the assembly of HPLC tool, which subjects to the eluting material to ultraviolet rays of pre-specified wavelength, and records the energy changes during this bombardment. Ultraviolet rays are high energy rays, with wavelength ranging from 10-400 nm. According to Plank's law, the shorter the wavelength, the larger is the amount of energy the rays carry. The energy of these ultraviolet rays is being absorbed by the molecules and the molecules get excited, and during the process of deexcitation the energy is released which is being recorded 
(a)

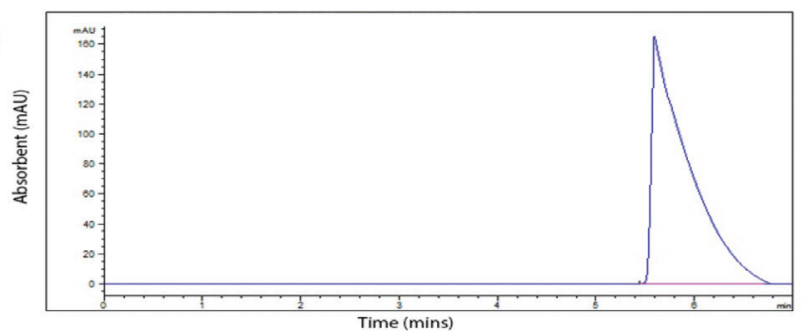

(b)

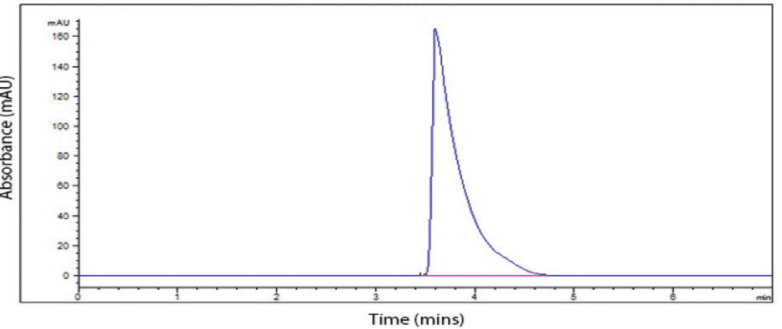

(c)

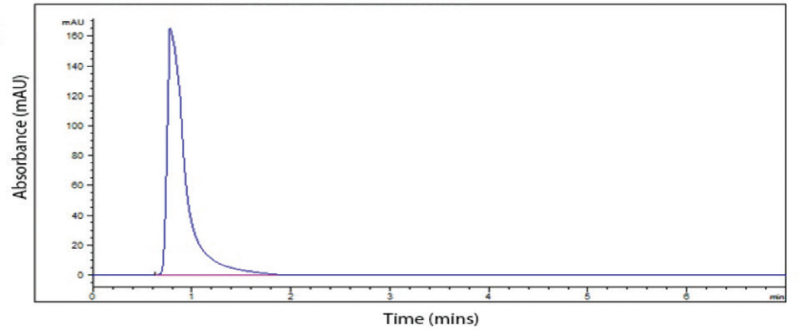

FIGURE 2. Comparison of change in retention time with change in flow rate of solvent (a) $0.5 \mathrm{~mL} / \mathrm{min}$, (b) $1.0 \mathrm{~mL} / \mathrm{min}$ and (c) $1.5 \mathrm{~mL} / \mathrm{min}$

by the detector and appear as a peak. Each species has a specific ultraviolet spectrum under which it responds, the energy of the spectrum corresponds to the bandwidth of its orbitals. At $205 \mathrm{~nm}$ wavelength, samples of both methanol and formic acid showed chromatographic peaks, 50\% solution of formic acid in methanol was analyzed and it gave two clear peaks.

Figure 3 shows the chromatogram of $50 \%$ solution of formic acid in methanol, by comparing the chromatograms of methanol and formic acid samples, it was analysed that earlier peak corresponds to methanol, while later peak is of formic acid.

\section{METHANOL PEAK EXCLUSION}

Owing to the presence of same hydroxyl group in the two compounds, methanol and formic acid, have a complexity that their chromatographic peaks appear at almost the same retention time. In Figure 2, it was observed that peaks for both species are appearing around retention time of $3 \mathrm{~min}$, and the two peaks are almost identical and are very close to each other. Under the presence of other reaction species, the $\mathrm{pH}$ of the reaction sample was expected to be changed; hence the two peaks could be confused with each other.

To avoid the ambiguity, the wavelength of the UV detector was tuned to a specific wavelength where formic acid peak appears while that for methanol would not appear. While increasing the wavelength from the maximum absorption spectra of methanol, i.e. $205 \mathrm{~nm}$, towards the maximum absorption spectra of formic acid, i.e. $256 \mathrm{~nm}$, it was observed that at $250 \mathrm{~nm}$ wavelength peaks of formic acid are clear and comprehendible while for methanol, no peak was observed at $250 \mathrm{~nm}$ wavelength. Detailed comparison at various concentrations has been shown in Figure 4. Hence, $250 \mathrm{~nm}$ wavelength was selected to exclude the peak of methanol and make the chromatogram understandable. Energy of $250 \mathrm{~nm}$ wavelength UV rays is less than that of $205 \mathrm{~nm}$ wavelength UV rays; hence, the UV rays are not able to excite the methanol molecules.

\section{DEVELOPMENT OF CALIBRATION CURVE AND ITS LINEARITY}

The position of the peak gives the identification that what specie is present in the sample. The amount of the specie present in the sample is calculated by finding the area under its peak. HPLC modules have this inbuilt capability of calculating the area under each peak, it needs to be specified in the report settings before starting the run otherwise the area is to be calculated using the cumbersome integration method. The HPLC report also shows the percentage of each specie in the sample but this percentage is based on the percentage area of each peak out of the cumulative area occupied by all the peaks. Percentages shown by HPLC report can be taken as a good approximation, but the data is not reliable when some of the peaks are excluded. Even when the peaks are not excluded intentionally, there is a possible presence of some specie, which might not give any peak at the specified conditions, or some of the area could be occupied by impurities. To calculate the right amount 


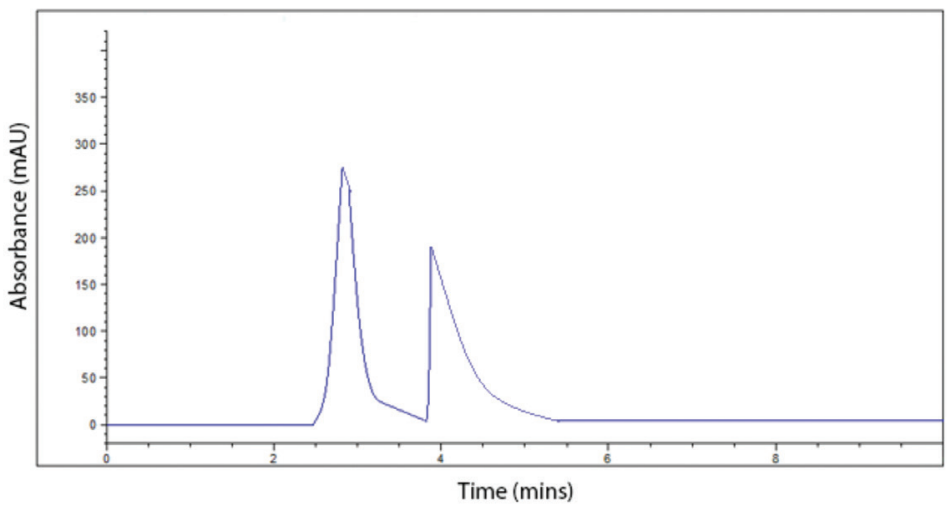

FIGURE 3. Chromatogram of $50 \%$ formic acid solution in methanol

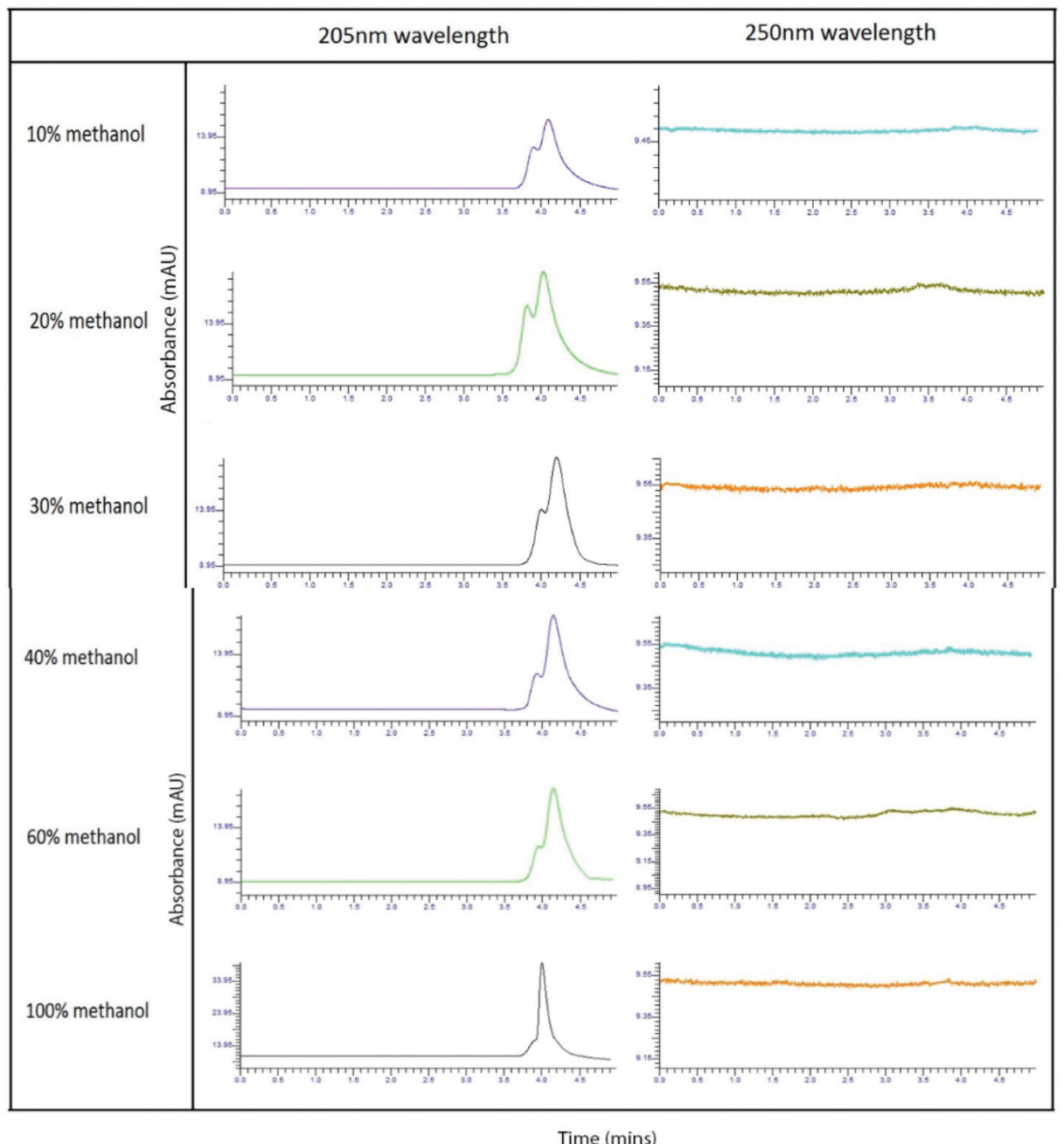

FIGURE 4. Exclusion of methanol peak by changing wavelength of detector from 205 to $250 \mathrm{~nm}$, methanol concentrations from $10 \%$ to $100 \%$

of species in a sample, it is better to make a calibration curve or data of area occupied by each standard solution of known concentration (Figure 5).

Known concentrations of formic acid were analyzed to find the area under their peaks. Figure 5 shows the response data against each concentration. Data showed a linear trend which could be best described by equation:

$$
y=66.701 x+616.28
$$

Response data $(\mathrm{mAU})=66.701 \times($ Percentage concentration of formic acid) +616.28

Krumen et al. (2004) have also shown that the response data, for Liquid Chromatography Mass Spectrometry, is almost linear against the concentration of the species under 


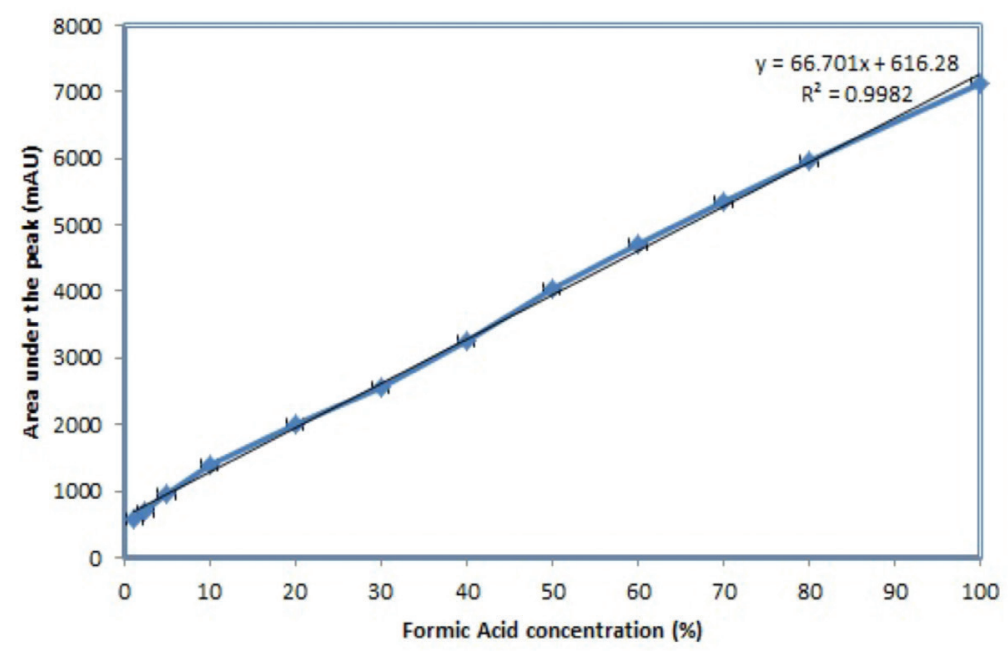

FIGURE 5. Linear curve for HPLC response data

analysis; the linear trend has also been reported for volatile fatty acids (Heuer et al. 2006) and leucine (an a-amno acid) (Godin et al. 2005). Linear trend of the data has validated our method. Linear trend has also given the possibility of using a linear equation to find the concentration of a species.

\section{LIMITS OF DETECTION}

In any analysis with given equipment there are certain limits of detection which are based on the sensitivity of the HPLC equipment. Each analysis method is reported to be valid within certain upper and lower limits of concentration. Below the lower detection limit, the changes in energy would be too small to be detected by the detector while above the upper detection limits the energy changes would be so high that it could actually burn out the detector or at least the signal would become irregular or bifurcated thus becoming not comprehendible.

Our HPLC method was validated between the concentrations of $1.25 \%$ formic acid in methanol up to $100 \%$ pure formic acid which shows the analytical parameters of the HPLC method. Statistical analysis of the trend line was also performed. Limits of Detection and Limits of Quantification were statistically calculated to be $2.25 \%$ and $6.83 \%$, respectively.

\section{EFFECT OF CHANGE IN WAVELENGTH ON LIMITS OF DETECTION}

Sometimes the concentrations of samples are not in the given range of limits of detection. The samples above the higher limits of detection are diluted and then the results of the signals are extrapolated. Samples with low detection or very low concentration are derivative to form species that are easily detectable (Morrison 2014; Shrivastava et al. 2011). However, these steps increase the probability of error in the analysis. The same could be achieved by tuning the wavelength of detector's ultraviolet rays, and subsequently receiving a controlled response signal, which could avoid the hassle of extrapolation.

Figure 6 shows that in formic acid analysis, when the detector's UV wavelength was shifted from 205 to $250 \mathrm{~nm}$, the response peak noticeably increased in height. Thus, to analyze samples of concentration higher than the upper detection limit, the wavelength of detector should be shifted away from the maximum absorption spectrum. To analyze samples of concentration below the lower detection limit, the wavelength of detector should be shifted towards the maximum absorption spectrum. However, with the change in wavelength, the response data would change so the calibration of response data needs to be done if the wavelength of detector is changed.

TABLE 1. Optimized analytical parameters for HPLC method

\begin{tabular}{cc}
\hline Parameters & Values \\
\hline Concentration range $(\mathrm{v} / \mathrm{v} \%$ formic acid) & $1.25-100$ \\
Regression equation & $\mathrm{y}=66.701 \mathrm{x}+616.28$ \\
& (Where $\mathrm{x}$ is concentration and $\mathrm{y}$ is peak area) \\
Intercept $\pm \mathrm{SD}$ & $616.28 \pm 45.6124$ \\
Slope $\pm \mathrm{SD}$ & $66.701 \pm 0.9057$ \\
Correlation coefficient $\left(\mathrm{R}^{2}\right)$ & 0.9982 \\
LOD $(\mathrm{v} / \mathrm{v} \%$ formic acid $)$ & 2.2 \\
LOQ $(\mathrm{v} / \mathrm{v} \%$ formic acid) & 6.83 \\
\hline
\end{tabular}




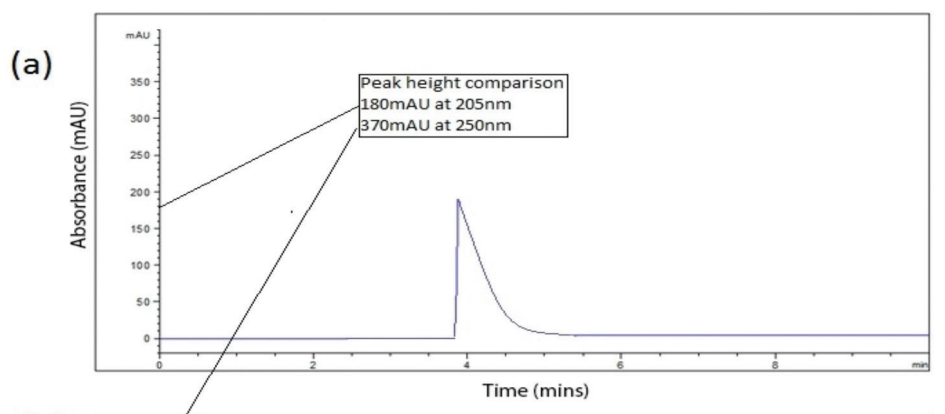

(b)

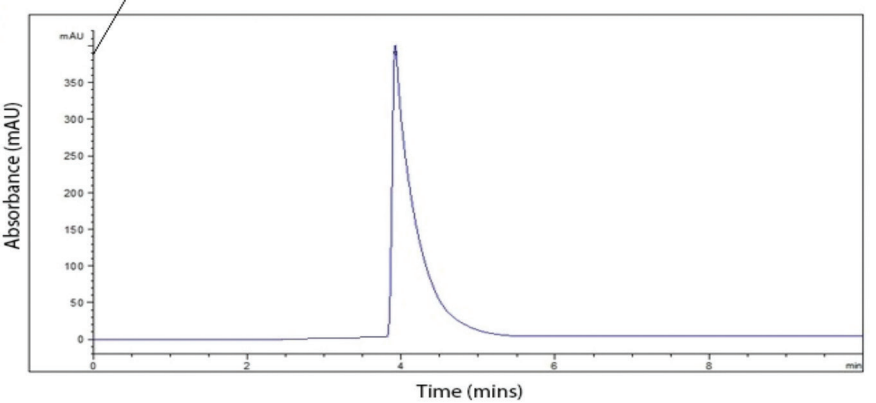

FIGURE 6. Change in detector's response with change in wavelength (a) $205 \mathrm{~nm}$ and (b) $250 \mathrm{~nm}$

\section{CONCLUSION}

Results of the present study showed that formic acid can be separated and analyzed through HPLC on a $25 \mathrm{~cm}$ long C-18 column, using water at a flow rate of $1 \mathrm{~mL} / \mathrm{min}$ as mobile phase and setting the wavelength of the ultraviolet detector at $250 \mathrm{~nm}$ wavelength.

Generally, we concluded that through the optimum tuning of the parameters, the utility of given equipment can be greatly increased by using the equipment for maximum analysis rather than searching for specific equipment for each analysis. The combination of nature of column and the solvent plays a vital role in the efficient separation of the constituents. The larger the dimensions of the column, the better the separation achieved due to a larger binding surface. Better and complete separation is achieved by decreasing the flow rate. The area under peak and the concentration have a linear trend. Magnitude of response of each constituent depends upon the chosen wavelength.

\section{ACKNOWLEDGEMENTS}

Authors are thankful to the deanship of scientific research at King Khalid University, Kingdom of Saudi Arabia for technical and administrative support.

\section{REFERENCES}

Ettre, L. 1993. Nomenclature for chromatography (IUPAC Recommendations 1993). Pure and Applied Chemistry 65(4): 819-872.

Godin, J.P., Hau, J., Fay, L.B. \& Hopfgartner, G. 2005. Isotope ratio monitoring of small molecules and macromolecules by liquid chromatography coupled to isotope ratio mass spectrometry. Rapid Communications in Mass Spectrometry 19(18): 2689-2698.
Hostettmann, K.M., Hostettmann, M. \& Marston, A. 1998. Preparative Chromatography Techniques Applications in Natural Product Isolation. 2nd ed. Berlin Heidelberg: Springer Berlin Heidelberg.

Heuer, V., Elvert, M., Tille, S., Krummen, M., Mollar, X.P., Hmelo, L.R. \& Hinrichs, K.U. 2006. Online $\delta 13 \mathrm{C}$ analysis of volatile fatty acids in sediment/porewater systems by liquid chromatography-isotope ratio mass spectrometry. Limnol. Oceanogr. Methods 4: 346-357.

Krummen, M., Hilkert, A.W., Juchelka, D., Duhr, A., Schlüter, H.J. \& Pesch, R. 2004. A new concept for isotope ratio monitoring liquid chromatography/mass spectrometry. Rapid Commun. Mass Spectrom. 18(19): 2260-2266.

Lee, X., Zhang, L., Huang, D., An, N., Yang, F., Jiang, W. \& Fang, B. 2013. Analysis of the stable carbon isotope composition of formic and acetic acids. Analytical Biochemistry 436(2): 178-186.

Levigne, S., Thomas, M., Ralet, M.C., Quemener, B. \& Thibault, J.F. 2002. Determination of the degrees of methylation and acetylation of pectins using a C18 column and internal standards. Food Hydrocolloids 16(6): 547-550.

McMurry, J. 2011. Organic Chemistry: With Biological Applications. 2nd ed. Belmont, CA: Brooks/Cole. p. 395.

McNaught, A.D. \& Wilkinson, A. 1997. Compendium of Chemical Terminology. IUPAC Recommendations. 2nd ed. USA: Blackwell Science.

Morrison, F.A. 2014. Obtaining Uncertainty Measures on Slope and Intercept of a Least Squares Fit with Excel's LINEST. Houghton, Michigan, USA Department of Chemical Engineering, Michigan Technological University. p. 25.

Mubeen, A.K., Sinha, S., Parashar, V. \& Khandekar, N. 2011. A validated NP-HPLC method for the determination of formic acid in pharmaceutical excipient imidurea. International Journal of Pharmaceutical and Biomedical Research 2(3): 140-144.

Shrivastava, A. \& Gupta, V. 2011. Methods for the determination of limit of detection and limit of quantitation of the analytical methods. Chronicles of Young Scientists 2(1): 21-25. 
Tagami, K. \& Uchida, S. 2008. Online stable carbon isotope ratio measurement in formic acid, acetic acid, methanol and ethanol in water by high performance liquid chromatographyisotope ratio mass spectrometry. Analytica Chimica Acta 614(2): 165-172.

Taylor, T. 2015. Important aspects of UV detection for HPLC. LCGC North America 33(11): 870.

Daniyal Hasan

School of Chemical and Materials Engineering

National University of Science and Technology

Sector H-12, Islamabad

Pakistan

Iram Mahmood *

Department of Industrial Engineering

College of Engineering

King Khalid University, Abha 61413

Kingdom of Saudi Arabia

Ishfaq Ahmad

Department of Mathematics and Statistics

Faculty of Basic and Applied Sciences

International Islamic University, Islamabad

Pakistan
Farah Aziz

Department of Public Health

Faculty of Applied Medical Sciences

King Khalid University Khamis Mushait

Kingdom of Saudi Arabia

Ishaq Ahmad

National Center for Physics

Islamabad, 44000

Pakistan

Ishaq Ahmad

NPU-NCP Joint International Research Center for

Advanced Nanomaterials and Defects Engineering

Northwestern Polytechnical University

Xi'an 710072

China

*Corresponding author; email: irahmad@kku.edu.sa

Received: 6 February 2019

Accepted: 7 March 2019 